\title{
Assessing needs for psychiatric treatment in prisoners: 2. Met and unmet need
}

\author{
Sharon Jakobowitz ${ }^{1}$ Paul Bebbington ${ }^{1}$ (i) $\cdot$ Nigel McKenzie $^{2} \cdot$ Rachel Iveson $^{3}$ • \\ Gary Duffield $^{3} \cdot$ Mark Kerr $^{4} \cdot$ Helen Killaspy ${ }^{1}$
}

Received: 3 August 2016/Accepted: 11 November 2016/Published online: 22 November 2016

(c) The Author(s) 2016. This article is published with open access at Springerlink.com

\begin{abstract}
Background In a companion paper, we established high levels of psychiatric morbidity in prisoners (Bebbington et al. Soc Psychiatry Psychiatr Epidemiol, 2016). In the current report, we evaluate how this morbidity translates into specific needs for treatment and the consequent implications for services. Mental health treatment needs and the extent to which they had been met were assessed in a representative sample of prisoners in a male and a female prison in London (Pentonville and Holloway).

Methods Prisoners were sampled at random in a sequential procedure based on the Local Inmate Data System. We targeted equal numbers of male remand, male sentenced, female remand, and female sentenced prisoners. Following structured assessment of psychosis, common mental disorders, PTSD, personality disorders and disorders of abuse, we used the MRC Needs for Care Assessment (NFCAS) to establish whether potential needs for care in ten areas of mental health functioning were met, unmet, or incapable of being met by services.
\end{abstract}

Paul Bebbington

p.bebbington@ucl.ac.uk

1 Division of Psychiatry, University College London, 6th Floor, Maple House, 149 Tottenham Court Road, London W1T 7NF, UK

2 Camden and Islington Foundation Trust, St Pancras Hospital, 4 St Pancras Way, London NW1 OPE, UK

3 North London Forensic Service, Chase Farm Hospital, The Ridgeway, Enfield, Middlesex EN2 8JL, UK

4 School of Social Policy, Sociology and Social Research, Faculty of Social Sciences, Cornwallis North East, University of Kent at Canterbury, Canterbury, Kent CT2 7NF, UK
Results Data on treatment experience were provided by 360 inmates. Eighty percent of females and $70 \%$ of males had at least one need for treatment. Over half $(53.7 \%)$ of the needs of female prisoners were met, but only one third $(36.5 \%)$ in males. Needs for medication were unmet in $32 \%$ of cases, while those for psychological treatment were unmet in $51 \%$.

Conclusions Unmet needs for mental health treatment and care were common in the two prisons. This has adverse consequences both for individual prisoners and for the effective functioning of the criminal justice system.

Keywords Prisoners - Psychiatric disorders · Psychosis · Needs for care · Treatment

\section{Introduction}

In our companion paper [1], we reported very high rates of psychiatric disorder in two London prisons. Fifteen years previously the 1997 British National Survey of Psychiatric Morbidity among Prisoners identified similar rates of disorder, and also severe problems in delivering psychiatric treatment to prisoners [2]. Thus, prisoners often asked for help with their problems, but were twice as likely to have had such requests turned down after entering prison than in the period immediately beforehand, indicating that prison-based services were performing poorly $[3,4]$. Provisions for rectifying this were set out in the late 1990s [5, 6]. The key principle was equity: prisoners should receive the same level of mental health care in prisons as they would in the wider community. To facilitate this, the National Health Service (NHS) was given responsibility for providing prison health care services in April 2006. 
It was envisaged that prison mental health services would be more effective if locally commissioned [7]. Severe mental illness was to be managed by teams equivalent to NHS Community Mental Health Teams. Although around 90 in-reach mental health teams were subsequently commissioned in prisons, problems in implementing effective services were reflected in considerable local inequalities in mental health spending [8].

Brooker and Gojkovic [9] obtained data from 53 English prison in-reach teams. Although deploying on average only five whole time staff equivalents, most in-reach teams covered more than one prison. The workload was considerable: $75 \%$ of teams took more than 50 referrals a month, and staff complained that face-to-face interaction with prisoners was very restricted. They found it hard to deal with the complex problems associated with prisoners' mental disorders, not helped by the lack of staff and expertise in prison primary care services.

The relationship between clients and medical services are traditionally subsumed under the concepts of demand, need, and utilisation. These concepts are distinct but related [10]. Demand is the requirement for services and treatments as seen by clients, and is based on lay knowledge, and lay concepts of disorder and treatment. Such concepts inevitably vary in their degree of sophistication, and are related to people's individual illness perceptions. Need is the requirement for services and treatments identified from the professional ("expert") perspective. It presupposes the identification of problems for which there are potentially effective interventions $[10,11]$. It does imply a constructive and respectful interaction between clinicians and clients, and will often tally closely with the demand perspective. Utilisation is the actual take-up of services and treatments, and is shaped by practical issues such as the availability of services and the relative cost and effectiveness of treatments. However, it is also affected by the attitude of people to their health, and by the real or perceived accessibility of services. Inadequate treatment may result variously from faulty recognition of requirements by clients and service providers, and inadequate provision of treatment resources.

While UK prison mental health services have improved, investment must be guided by a clear account of the actual treatment needs of prisoners and their overall scale. Studies of the prevalence of psychiatric disorders in prisons give an idea of the burden of disorder. However, prevalence is merely a count of diagnosed cases, and there are problems in using it to determine service provision. It can only suggest the sorts of treatment and services required. It is thus unclear how the observed rates of mental illness in prison translate into specific requirements for treatment, or how the NHS services now responsible for their care should be configured. Prevalence information can be augmented by direct assessments of individual need $[10,12,13]$, as clinicians quite properly do not base either their decisions to offer treatment or their choice of particular treatments purely on diagnosis; they take account of the way symptoms have evolved, how long they have lasted, the associated distress and impairment of social performance, and the possibility that symptoms will resolve quickly without treatment. Moreover, clients' views must also be taken into account. However, clinician-defined needs assessments have an appreciable potential for idiosyncrasy, being dependent on individual clinical values that are often strongly held. An assessment of needs for treatment for research purposes therefore requires the standardisation of procedures for applying clinical judgements to need.

The purpose of the Assessing Needs for Psychiatric Treatment in Prisoners (ANPTP) project was (1) to quantify overall levels of the need for mental health care and treatment in prisoners, (2) to identify specific conditions requiring treatment, and (3) to assess how far these needs were met by the various mental health facilities in prison. To do this, we used a procedure that operationalises judgements of need, the Needs for Care Assessment (NFCAS [10, 13]). We chose this because it had been used in general population surveys $[14,15]$, and in preference to the forensic version of the Camberwell Assessment of Need [16], which in our view tends too much to conflate need and demand.

Our research was based in two prisons dealing with local remanded and sentenced prisoners, in which the responsibility for psychiatric services lay with local NHS Trusts. HMP Holloway was a female prison with an operational capacity of 512, while HMP Pentonville accommodated around 1200 male prisoners. Psychiatric services were reasonably well-organised, albeit provided by a range of agencies. Mood disorders were generally the province of primary care, with a process of triage governing referral to Community Mental Health In-reach Teams. Cases of psychosis were generally assessed and managed by the Inreach Teams. Psychological treatment and counselling were shared between voluntary providers and the prison psychology service. There were specific provisions for drug and alcohol problems, including detoxification regimes, and group and individual programmes of treatment. However, considerable staff turnover meant specific services sometimes became unavailable.

\section{Methods}

Prisoners were randomly sampled in equal numbers from the following groups: male remand; female remand; male sentenced; female sentenced. The sequential sampling procedure and its rationale are described in detail in the companion paper [1], as are the instruments for identifying psychiatric disorder. Participants were interviewed in a single phase. 


\section{Instruments}

We used the NFCAS [13] to establish how far psychiatric services were successful in identifying and meeting the needs for treatment of prisoners with psychiatric disorders, and to what extent prisoners were willing to accept such treatment. Treatments were considered in detail and included pharmacotherapy, and a range of different sorts of psychological treatments. This allows inferences about the demands on services if all needs were met. The NFCAS standardises the coverage of both disorders and treatments, and then links disorders with treatment through rules that define need operationally [10]. Explicit guidelines and examples are incorporated in a manual. In the prison setting, we used the Community Version, as inmates were ostensibly incarcerated from the community without regard to their mental health status $[13,17,18]$. This version was designed to approximate, in a more itemised and systematic manner, the functioning of well-organised primary care and psychiatric services. Its reliability was established by Lesage et al. [19].

The definition of a primary need for care requires two distinct criteria (1) the person's functioning falls below, or threatens to fall below, some minimum specified level (in the community context, this means significant distress from symptoms, with or without disablement), and (2) this is potentially remediable or preventable. For each area of clinical functioning covered, the assessment specifies the threshold for identifying impaired functioning and a set of appropriate interventions or items of care. Needs for care in each area are then determined by comparing the actual items of care provided with a model of what those items of care should be, based on the literature on treatment efficacy, particularly where this forms the basis of contemporary UK national guidelines.

Unlike conventional measures of symptoms and behaviour, the assessment uses data on level of functioning to identify the appropriate actions to be taken by clinicians. Needs are defined in terms of these actions, i.e. the offer of specific items of care.

The primary need status in each area of functioning falls into the categories:

- met need: appropriate action is already being undertaken

- unmet need: there is some action appropriate now that has not been undertaken

- no need: there is no clinical problem requiring treatment

- no meetable need: there is disablement but no action that is both appropriate and feasible.
Where unmet needs were identified, clinical judgements were made of the significance of the consequences for the prisoner's well-being (mild, moderate or severe).

As the basis for identifying need, the authors of the instrument stipulated how long symptoms must last before treatment should be considered necessary; they took as their threshold the presence of clinically significant (i.e. moderate or severe rather than mild) psychiatric symptoms or disability over a period of 6 weeks. We evaluated needs in relation to specific areas of functioning: positive psychotic symptoms; depressive symptoms; anxiety and obsessional symptoms; adjustment disorder clearly secondary to an external event or circumstance; posttraumatic stress disorder; personality disorder; problems with alcohol; and problems with drugs (we did assess eating disorders, but these, perhaps surprisingly, were identified only in three women prisoners). While actual services differ considerably in resource and philosophy of care, this is deliberately not taken into account. To compare services, unmet needs in a given service are rated without considering whether particular items of care are routinely provided, or whether the staffing and expertise exists to provide them.

In this study, a panel of clinical assessors made consensus judgements of treatment needs on the basis of presentations of the available information by SJ. The panel included PB and NM, then the clinical leads for prison mental health care in HMP Holloway and HMP Pentonville, together with other members of the research team when available).

The NFCAS requires information about mental state and the course of disorder, social functioning, social stresses, the treatment received and the service users' attitudes towards them. These requirements were met by a range of instruments.

Where possible and appropriate we used the same instruments for defining aspects of the mental state as the ONS Prisons Survey [2], as described fully in the companion paper [1]. They included the Revised Version of the Clinical Interview Schedule (CIS-R) [20] to assess neurotic symptoms and common mental disorders. We used information from the Life Events and Difficulties Schedule [21] to decide where affective symptoms should be interpreted as adjustment disorder. Psychotic disorders were assessed using SCAN [22, 23]. We also used the Structured Clinical Interview for DSM-IV [24] to identify personality disorder, and the Posttraumatic Stress Diagnostic Scale (PDS [25]). Alcohol misuse and dependence was assessed from the Alcohol Use Disorders Identification Test (AUDIT [26]) and the Severity of Alcohol Dependence Questionnaire (SAD-Q [27]). Drug dependence was identified from the questions in the ONS prison survey [2]. 
The Social and Occupational Functioning Assessment Scale (SOFAS) [28] is a simple measure of social functioning rated without consideration of the level of mental disturbance.

Finally, we used a structured interview to collect detailed information about potential and actual psychiatric treatments, and participants' views about treatments offered or appropriate for their psychiatric symptoms. Their views are important as they are grounds for discriminating between unmet and unmeetable need: where participants reject treatment either specifically or as a general principle, ostensible needs must then be rated as unmeetable.

In the current report, we present straightforward crosstabulations of need status in male and female and in remanded and sentenced prisoners with Chi-square tests of significance.

\section{Results}

Ten sentenced and ten remand prisoners were sampled per month. The sampling procedure is described in the companion paper [1]. We interviewed 197 male and 171 female prisoners with an overall response rate of $70 \%$. Most failures were due to unpredicted unavailability, rather than to refusal, and we were unable to obtain information on nonresponders with any consistency. We also failed to collect information about treatment for five male and three female interviewed prisoners. Sociodemographic characteristics are described in the companion paper [1].

Seventy-five percent of prisoners had at least one clinical condition for which treatment should have been considered, somewhat more so in women than in men (Table 1). In a minority, identified disorders were in abeyance, but with a significant risk of recurrence requiring continuing treatment and surveillance. In particular, alcohol and drug abuse is (almost totally) constrained in prison, and intervention is therefore aimed at minimising the risk of resumption on discharge.
The overall prevalence of psychosis was particularly striking. It was significantly more common in remanded than in sentenced, and in female than in male prisoners. However, depression was a more prevalent clinical problem, being present in around $34 \%$ of male and $45 \%$ of female prisoners. Rates for anxiety as a clinically significant problem were lower. This is because, in many prisoners, anxiety symptoms were relatively mild and not very disturbing or disabling, while in others the clinical picture was dominated by depressive symptoms, so we subsumed the anxiety symptoms under the rubric of depression. This is reflected in the concurrence of these two disorders: $16 \%$ of prisoners with depression also had a separate anxiety disorder, whereas three-quarters of cases of anxiety also had depression. In other instances, relatively mild depressive or anxious symptoms could be wholly attributed to the difficulties of adjusting to the fact of imprisonment and the demands of prison life. Where such symptoms were persistent, this generally led to their being recorded as an adjustment disorder.

Overall, 5\% of prisoners were deemed to have adjustment disorders, sometimes related to the stresses attendant on imprisonment, sometimes to ongoing situations outside the prison. This low rate is the result of the NFCAS criterion that, to be registered, disorders must be present for 6 weeks. PTSD is distinct from adjustment disorder, both by the extreme nature of the stressor involved and by its specific symptoms. Eight percent of prisoners were currently suffering from posttraumatic stress disorder. Depression, anxiety, adjustment disorder, and PTSD comprise a general category of affective disorders. Forty-nine percent of prisoners suffered from affective disorder so defined (55.6\% of women, $43.2 \%$ of men).

The identification of personality disorder in prisoners is problematic, particularly as the inclusion criteria for antisocial personality disorder include criminal activity and the responses to it of the criminal justice system. In the NFCAS, we identified personality disorder on the basis of additional characteristics for which it would be appropriate to consider treatment. As recorded in Table 1, this resulted
Table 1 Prevalence of significant clinical problem by sex and sentencing category

\begin{tabular}{lcccccc}
\hline Problem & Male $(\%)$ & Female $(\%)$ & Total $(\%)$ & Remand $(\%)$ & Sentenced (\%) & Total (\%) \\
\hline Psychosis & $22(11.5)$ & $9(5.4)^{*}$ & $31(8.6)$ & $21(12 .)^{+}$ & $10(5.9)$ & $31(8.6)$ \\
Depression & $65(33.9)$ & $76(45.2)^{*}$ & $141(39.2)$ & $73(42.2)$ & $68(36.7)$ & $141(39.2)$ \\
Anxiety & $17(8.5)$ & $12(7.1)$ & $29(8.1)$ & $18(10.4)$ & $11(5.9)$ & $29(8)$ \\
Adjustment disorder & $8(4.2)$ & $11(6.5)$ & $19(5.3)$ & $9(5.2)$ & $10(5.3)$ & $19(5.3)$ \\
PTSD & $9(4.7)$ & $20(11.9)^{*}$ & $29(8.1)$ & $14(8.1)$ & $15(8)$ & $29(8)$ \\
Personality disorder & $31(16.1)$ & $33(19.6)$ & $64(17.8)$ & $32(18.5)$ & $32(17)$ & $64(17.2)$ \\
Alcohol abuse & $75(39.1)$ & $74(44)$ & $149(41.4)$ & $76(43.9)$ & $73(38.2)$ & $149(41.3)$ \\
Substance abuse & $79(41.1)$ & $86(51.2)$ & $165(45.8)$ & $91(52.6)^{+}$ & $74(39.4)$ & $165(45.7)$ \\
\hline Male vs female: * $* 0.05 ;$ remand vs sentenced ${ }^{+} p<0.05$ & &
\end{tabular}

Male vs female: ${ }^{*} p<0.05$; remand vs sentenced: ${ }^{+} p<0.05$ 
in prevalence lower than in the National Prisoners Survey, generally because criminality of itself did not necessarily indicate to us a need for psychiatric treatment [29]. Thus, we identified around $18 \%$ of male and female prisoners as having personality disorder meriting a consideration of treatment.

The really striking feature in Table 1 is the very high prevalence of problems with alcohol and drug abuse. Overall, $41 \%$ of prisoners had problems with alcohol, and $46 \%$ with drug abuse. These problems were often linked: of the 225 prisoners with one or other of these conditions, 89 (39.6\%) had both.

Depression, alcohol abuse and drug abuse are likely to reinforce each other, and there was considerable overlap: of the 225 prisoners who had one of these conditions, 51 $(22.7 \%)$ had all three. Of 141 prisoners with depression, $105(73.9 \%)$ had at least one abuse disorder, whereas fewer than half those who abused alcohol or drugs were depressed.

In Table 2 we present the need and treatment status of the various disorders. In people with psychotic conditions, about half of all needs were met, and about a tenth could not be met because of external constraints, mainly the refusal of prisoners to countenance treatment. However, a need for some kind of treatment identified as appropriate remained unmet in $40 \%$ of prisoners with psychotic problems. Levels of unmet need were greater in male than in female prisoners, and in remand than in sentenced prisoners, though not significantly so. Antipsychotic medication is of course a mainstay of treatment in psychosis, and a failure, at least to consider it, is reproachable. While three prisoners explicitly rejected offers of medication, around a quarter had an unmet need for it, predominantly where their condition had gone unrecognised. In two female cases, the prescription of medication was rated as an overprovision, since their symptoms had abated more than a year ago and their medication had not been reviewed.

Just over a third of prisoners with depressive conditions had their needs for treatment met, nearly $60 \%$ did not. However, there was a marked sex difference: needs for treatment was unmet in three-quarters of male prisoners. This was unlikely to be due to a more limited availability of treatment in HMP Pentonville. A more plausible explanation lies in a tendency for male prisoners to acknowledge depressive symptoms less readily, together with a relative failure of surveillance of such symptoms in the men's prison. This finding may also be partly explained by the fact that one third of prisoners had been in Pentonville for under a month. Many prisoners experienced low mood during their first few weeks in prison and it is not a straightforward matter for prison staff to identify those needing referral to primary care for treatment. Even when an appointment to see a GP had been arranged, prisoners would often be moved to another prison before the assessment.

Anxiety disorders were often comorbid with other conditions, and this required a judgement about which condition was the primary and appropriate target of treatment. Nevertheless, the situation regarding treatments for anxiety was similar to that seen in depressive disorders, with many unmet needs.

The relative mildness of identified adjustment disorders may be reflected in the fact that most needs for treatment went unmet, probably because they were overlooked.

In all, 19 prisoners $(8.1 \%)$ were assessed as requiring treatment for PTSD (Table 2). In two further cases, the need for treatment for PTSD was subsumed under treatment for a different clinical problem. The identification and treatment of this disorder was poor in both prisons: $90 \%$ of identified needs were unmet.

Historically, psychiatrists and clinical psychologists have been pessimistic about the treatability of personality disorder. However, many people diagnosed with personality disorders are survivors of abuse, particularly in prisons. There are known ways of dealing with both the emotional and the behavioural consequences of abuse, primarily involving psychological techniques. We used the Needs for Care Assessment to judge whether individual prisoners might respond to such interventions if offered. In two thirds of both male and female cases needs went unmet. Interestingly, these prisoners were relatively rarely rated as having unmeetable need-in other words they were amenable in principle to being treated (Table 2).

Both prisons in this study were committed to offering interventions to prisoners with alcohol problems, particularly in the form of individual and group psychological treatments. One in seven of identified needs were rated as unmeetable, usually due to prisoners' reluctance to accept treatment. There was no gender difference in unmeetable need. However, a majority of meetable needs went unmet in male prisoners, whereas they were largely met in women.

Drug abuse was the most prevalent condition in these prisoners. Again, the prisons have well developed systems and interventions to help inmates with such problems, and nearly $60 \%$ of needs were met. Once more, an appreciable number of prisoners declined involvement in what was judged appropriate treatment.

Table 3 records our evaluation of the overall delivery of appropriate treatments. Taking all treatments together, around $10 \%$ of needs were unmeetable, while $44.7 \%$ were met and $45.3 \%$ unmet. Women's treatment needs were significantly more likely to be met than those of men. Specific needs for medication were more likely to be met (59\%), and again significantly more so in women. The deployment of psychological treatments, broadly 
Table 2 Overall need status for treatment of different disorders

\begin{tabular}{|c|c|c|c|c|c|}
\hline Disorder/need status & Male & Female & Remand & Sentenced & Total \\
\hline Psychosis $(N)$ & 22 & 8 & 11 & 19 & 30 \\
\hline Met $(\%)$ & $10(45.5)$ & $5(62.5)$ & $4(36.4)$ & $11(57.9)$ & $15(50)$ \\
\hline Unmet $(\%)$ & $10(45.5)$ & $2(25)$ & $5(45.5)$ & $7(36.8)$ & $12(40)$ \\
\hline Unmeetable (\%) & $2(9.0)$ & $1(12.5)$ & $2(18.1)$ & $1(5.3)$ & $3(10)$ \\
\hline Depression $(N)$ & 50 & 63 & 55 & 58 & 113 \\
\hline Met $(\%)$ & $10(20)$ & $32(50.8)^{* *}$ & $21(38.2)$ & $21(36.2)$ & $42(37.2)$ \\
\hline Unmet $(\%)$ & $37(74)$ & $28(44.4)$ & $30(54.5)$ & $35(60.3)$ & $65(57.5)$ \\
\hline Unmeetable (\%) & $3(6)$ & $3(4.8)$ & $4(7.3)$ & $2(3.4)$ & $6(5.3)$ \\
\hline Anxiety $(N)$ & 8 & 3 & 4 & 7 & 11 \\
\hline Met $(\%)$ & $2(25)$ & $1(33.3)$ & $2(50)$ & $1(14.3)$ & $3(27.2)$ \\
\hline Unmet $(\%)$ & $6(75)$ & $1(33.3)$ & $2(50)$ & $5(71.4)$ & $7(63.7)$ \\
\hline Unmeetable (\%) & 0 & $1(33.3)$ & 0 & $1(14.3)$ & $1(9.1)$ \\
\hline Adjustment disorder $(N)$ & 6 & 6 & 6 & 6 & 12 \\
\hline Met (\%) & 0 & $2(33.3)$ & $1(16.7)$ & $1(16.7)$ & $2(16.7)$ \\
\hline Unmet $(\%)$ & $5(83.3)$ & $4(66.7)$ & $5(83.3)$ & $4(66.6)$ & $9(75)$ \\
\hline Unmeetable (\%) & $1(16.7)$ & 0 & 0 & $1(16.7)$ & $1(8.3)$ \\
\hline PTSD $(N)$ & 5 & 14 & 10 & 9 & 19 \\
\hline Met $(\%)$ & $1(20)$ & $1(7.1)$ & $1(10)$ & $1(11.1)$ & $2(10.5)$ \\
\hline Unmet $(\%)$ & $4(80 \%)$ & $13(92.9 \%)$ & $9(90 \%)$ & $8(88.9 \%)$ & $17(89.5 \%)$ \\
\hline Unmeetable (\%) & 0 & 0 & 0 & 0 & 0 \\
\hline Personality disorder $(N)$ & 16 & 19 & 21 & 14 & 35 \\
\hline Met $(\%)$ & $4(25)$ & $7(36.8)$ & $7(33.3)$ & $4(28.6)$ & $11(31.4)$ \\
\hline Unmet $(\%)$ & $11(68.7)$ & $11(57.9)$ & $13(61.9)$ & $9(64.3)$ & $22(62.9)$ \\
\hline Unmeetable (\%) & $1(6.3)$ & $1(5.3)$ & $1(4.8)$ & $1(7.1)$ & $2(5.7)$ \\
\hline Alcohol abuse $(N)$ & 57 & 66 & 55 & 68 & 123 \\
\hline Met $(\%)$ & $20(35.1)$ & $38(57.6)^{*}$ & $27(49.1)$ & $31(45.6)$ & $58(47.2)$ \\
\hline Unmet $(\%)$ & $28(49.1)$ & $19(28.8)$ & $23(41.8)$ & $24(35.3)$ & $47(38.2)$ \\
\hline Unmeetable (\%) & $9(15.8)$ & $9(13.6)$ & $5(9.1)$ & $13(19.1)$ & $18(14.6)$ \\
\hline Drug abuse $(N)$ & 65 & 75 & 61 & 79 & 140 \\
\hline Met $(\%)$ & $35(53.8)$ & $48(64)$ & $32(52.5)$ & $51(64.6)$ & $83(59.3)$ \\
\hline Unmet (\%) & $24(36.9)$ & $16(21.3)$ & $19(31.1)$ & $21(26.6)$ & $40(28.6)$ \\
\hline Unmeetable (\%) & $6(9.3)$ & $11(14.7)$ & $10(16.4)$ & $7(8.8)$ & $17(12.1)$ \\
\hline
\end{tabular}

Male vs female: $* p<0.05$; ** $p<0.01$ conceived, was almost as good, with half the need being met, again more so in women. However, many of the psychological treatments comprised counselling, delivered through the relatively well-organised services for drug and alcohol problems. More than half the psychological treatment needs for these disorders were met, in contrast to fewer than $40 \%$ for other disorders (Table 4 ).

Figure 1 presents our judgements of the consequences of unmet needs for the well-being of the prisoner. These were more severe in cases of depression, psychosis, personality disorder, and PTSD. These data indicate where increased effort on the part of prison mental health services might yield the greatest numerical or individual benefit. The utilitarian view would advise a focus on depression, alcohol and substance abuse, while equity would argue redoubled effort to treat psychosis, personality disorder and PTSD.

\section{Discussion}

In the companion paper, we reported very high prevalence rates for mental disorders using standardised diagnostic instruments [1]. The procedures used here were somewhat different. We combined diagnostic and other clinical information to identify people for whom some form of treatment should be considered. In general, this would reduce prevalence by excluding relatively mild disorders likely to be self-limiting. The existing literature about the prevalence of mental disorders in prison can therefore be 
Table 3 Overall success in meeting treatment needs

\begin{tabular}{lccccc}
\hline Treatment & Male & Female & Remand & Sentenced & Total \\
\hline All treatments $(N)$ & 229 & 254 & 223 & 260 & 483 \\
Met $(\%)$ & $82(35.8)$ & $134(52.8)^{* *}$ & $95(42.6)$ & $121(46.5)$ & $216(44.7)$ \\
Unmet $(\%)$ & $125(54.6)$ & $94(37.0)$ & $106(47.5)$ & $113(43.5)$ & $219(45.3)$ \\
Unmeetable $(\%)$ & $22(9.6)$ & $26(10.2)$ & $22(9.9)$ & $26(10.0)$ & $48(9.9)$ \\
Medication $(N)$ & 47 & 55 & 56 & 46 & 102 \\
Met $(\%)$ & $17(36.2)$ & $43(78.2)^{* *}$ & $35(62.5)$ & $25(54.3)$ & $60(58.8)$ \\
Unmet $(\%)$ & $23(48.9)$ & $10(18.2)$ & $16(28.6)$ & $17(37.0)$ & $33(32.4)$ \\
Unmeetable $(\%)$ & $7(14.9)$ & $2(3.6)$ & $5(8.9)$ & $4(8.7)$ & $9(8.8)$ \\
Psychological treatments $(N)$ & 125 & 189 & 153 & 161 & 314 \\
Met $(\%)$ & $54(43.2)$ & $100(52.9)$ & $77(50.3)$ & $77(47.8)$ & $154(49.0)$ \\
Unmet $(\%)$ & $52(41.6)$ & $66(34.9)$ & $54(35.3)$ & $64(39.8)$ & $118(37.6)$ \\
Unmeetable $(\%)$ & $19(15.2)$ & $23(12.2)$ & $22(14.4)$ & $20(12.4)$ & $42(13.4)$ \\
\hline
\end{tabular}

Male vs female: $* * p<0.01$

\begin{tabular}{llllll}
\hline Disorder categories & Male & Female & Remand & Sentenced & Total \\
\hline All disorders $(N)$ & 125 & 189 & 153 & 161 & 314 \\
Met $(\%)$ & $54(43.2)$ & $100(52.9)$ & $77(50.3)$ & $77(47.8)$ & $154(49.0)$ \\
Unmet $(\%)$ & $52(41.6)$ & $66(34.9)$ & $54(35.3)$ & $64(39.8)$ & $118(37.6)$ \\
Unmeetable $(\%)$ & $19(15.2)$ & $23(12.2)$ & $22(14.4)$ & $20(12.4)$ & $42(13.4)$ \\
Alcohol and drug abuse only $(N)$ & 68 & 108 & 91 & 85 & 176 \\
Met $(\%)$ & $33(48.5)$ & $66(61.1)$ & $55(60.4)$ & $44(51.8)$ & $99(56.3)$ \\
Unmet $(\%)$ & $22(32.4)$ & $25(23.1)$ & $20(22.0)$ & $27(31.8)$ & $47(26.7)$ \\
Unmeetable $(\%)$ & $13(19.1)$ & $17(15.7)$ & $16(17.6)$ & $14(16.5)$ & $30(17.0)$ \\
Excluding alcohol and drug abuse $(N)$ & 57 & 81 & 62 & 76 & 138 \\
Met $(\%)$ & $21(36.8)$ & $34(42.0)$ & $22(35.5)$ & $33(43.4)$ & $55(39.9)$ \\
Unmet $(\%)$ & $30(52.6)$ & $41(50.6)$ & $34(54.8)$ & $37(48.7)$ & $71(51.4)$ \\
Unmeetable $(\%)$ & $6(10.5)$ & $6(7.4)$ & $6(9.7)$ & $6(7.9)$ & $12(8.7)$ \\
\hline
\end{tabular}

Table 4 Psychological treatment needs and disorder categories

Fig. 1 The significance of unmet need

no more than a frame of reference for our specific findings [30]. Nevertheless, we found a majority of prisoners had mental disorders significantly affecting their behaviour,

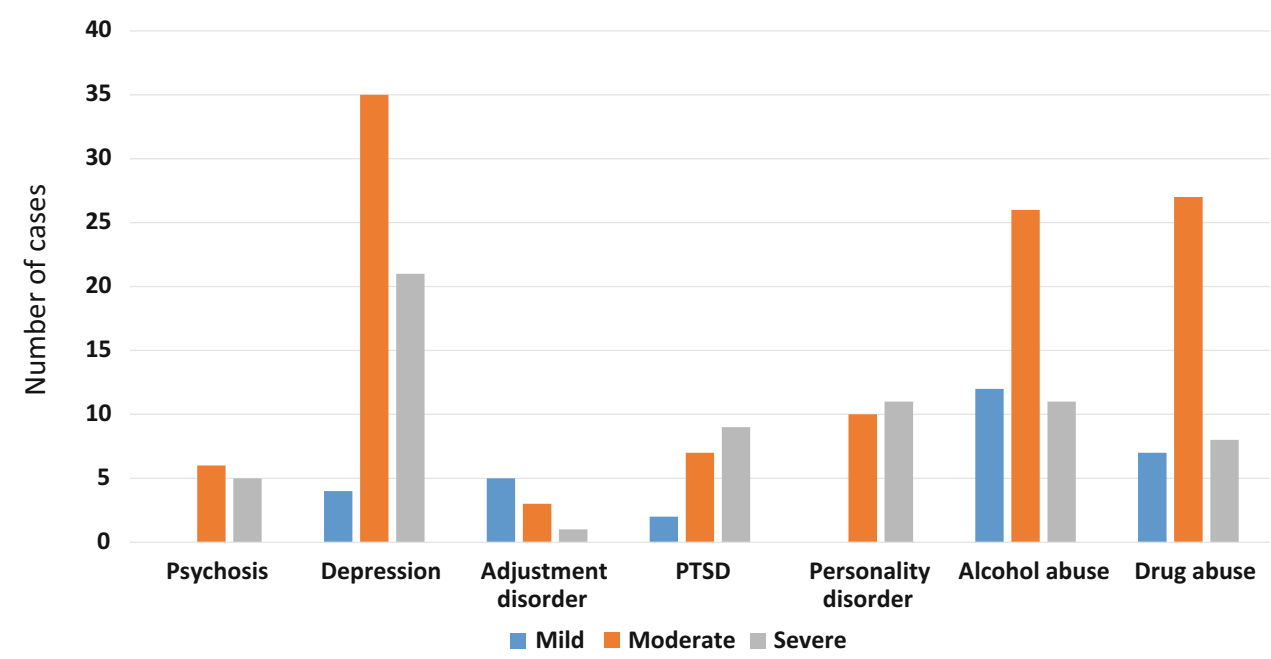

functioning and well-being, for which treatment ought therefore to be considered. The disorders with the highest prevalence rates were depression, alcohol problems and 
substance abuse. The high prevalence of psychotic disorders identified here as having needs for treatment are commensurate with the SCAN-based diagnoses in the companion paper, where the issue of prevalence is discussed. These disorders were not substance-related.

Comorbidity was also very frequent: this creates particular difficulties for the effective provision and deployment of mental health services in prisons, especially if the disorders are of different types (e.g. a mental disorder in tandem with substance abuse problems). In contrast, interventions outside the prison environment will capture relatively few people with multiple disorders, even though comorbidity will affect responses to treatment [31].

Over $80 \%$ of female and $70 \%$ of male prisoners were identified as needing treatment for a psychiatric condition. Our results do show that efforts were being made in both prisons to identify people in need, and to offer them treatment. Nevertheless, of meetable needs, half were met and half unmet, a significant failure of recognition somewhere in the process of assessment. Assessment operates through a series of filters (recognition by reception staff, by officers working in the body of the prison, and by more specialist staff of one sort or another). Thus, the identification of need arises from the interaction between staff and prisoners, and can fail for a variety of reasons: staff may not ask, and prisoners may not tell.

Only $10 \%$ of needs were judged unmeetable: it was four times more likely that treatment was not offered than that it would be declined. Needs for medication were met more often than needs for psychological treatments (around 70\% compared with 50\%). However, the delivery of psychological treatments was inflated by the counselling afforded in the drug and alcohol programmes. Otherwise, only $40 \%$ of psychological treatment needs were met. Indeed, other than in the drug and alcohol programmes there was virtually no provision for psychological treatment in Pentonville prison during the course of this study. Indeed male prisoners fared worse than females in several ways. Depression was often unrecognised in male prisoners. Consequently, even the relatively straightforward prescription of medication was only provided in a third of appropriate cases. While half the treatment needs for alcohol problems were met overall, women prisoners were again better served. Treatment of substance abuse was generally better than for alcohol problems, and it was only here that the provision for men approached in quality that experienced by women prisoners.

Rating that a need has been met does not of course guarantee the intervention will be successful, only that it is a rational attempt to deal with a clinical problem in the context of our current knowledge of effectiveness. In the absence of anything better, even an unreliably effective treatment is a rational choice.
It should be noted that similar failures also characterize treatment provision in the general population [14, 15], although the situation may have improved over the last 20 years [32]. However, disorders in prison are more severe $[1,2]$, and for many in our study the consequences of unmet need appeared serious. Prison mental health services remain under-resourced [9], prison regimes do not conduce to effective treatment delivery, and incarceration disrupts treatment planning. Diversion schemes need to be maximised so imprisonment is avoided where possible. This requires the active and effective cooperation of community mental health trusts. These requirements have been acknowledged for 20 years but without effective implementation of policy.

\section{Strengths and limitations}

The study involves a large and representative sample of prisoners from two general prisons in London. We used standard diagnostic instruments, and an intensive technique for the assessment of needs and the extent to which they had been met. This has never been done before in a prison setting. Our findings are striking, and we have no reason to expect that treatment is delivered more effectively in other, similar prisons [9]. We inevitably missed a proportion of prisoners who were discharged or moved quickly; this places constraints on our findings, particularly if they were diverted specifically for mental health reasons.

\section{Conclusions}

We have documented particular and serious problems with the psychiatric and psychological treatment of people in prisons. The limited availability of suitable placements often seriously disrupted the necessary continuity of care. Without warning, prisoners might be released from courts or transferred to other prisons, which was very disruptive to after-care arrangements. Many prisoners lack a settled destination on release [33], and few can access the stabilising effects of employment. Shorter periods of imprisonment are particularly likely to cause problems with mental health treatment as they impair access to mental health services in prison. The prisoner's community tenure has consequently been disrupted with no compensatory opportunity for improvements to their mental health. This should be acknowledged in considerations of sentencing policy.

In each case we estimated the significance of unmet need. This gives an idea of the impact of any future improvement in services. These will require the modification of demand, the recognition of need, and the extension of resource. Effort put into the treatment of depression, and 
alcohol and substance abuse services would be valuable because, although the unmet need was not judged important in every case, the prevalence of these conditions was high, and this is therefore where most cases of significant unmet need were located. On the other hand, much of the unmet need for psychosis, PTSD and personality disorder was regarded as having major consequences for the individual concerned.

Acknowledgements Thanks to Mr Bruce Buckmaster, our service user advisor. This study was funded by the National Forensic Mental Health R\&D Programme (Ref. MRD 12/83).

\section{Compliance with ethical standards}

Ethical approval was obtained from the Thames Valley Research Ethics Committee (Ref. 05/MRE 12/52), in line with the 1964 Declaration of Helsinki and its later amendments.

The authors confirm that they have no financial involvement or affiliation with any organisation whose financial interests may be affected by material in the manuscript, or which might potentially bias it.

Open Access This article is distributed under the terms of the Creative Commons Attribution 4.0 International License (http://crea tivecommons.org/licenses/by/4.0/), which permits unrestricted use, distribution, and reproduction in any medium, provided you give appropriate credit to the original author(s) and the source, provide a link to the Creative Commons license, and indicate if changes were made.

\section{References}

1. Bebbington P, Jakobowitz S, McKenzie N, Killaspy H, Iveson R, Duffield G, Kerr M (2016) Assessing needs for psychiatric treatment in prisoners: 1. Prevalence of disorder. Soc Psychiatry Psychiatr Epidemiol. doi:10.1007/s00127-016-1311-7

2. Singleton N, Meltzer H, Gatward R, Coid J, Deasy D (1998) Psychiatric morbidity among prisoners in England and Wales. TSO, London

3. Coid J, Petruckevitch A, Bebbington P, Brugha D, Jenkins R, Farrell M, Lewis G, Singleton N (2002) Ethnic differences in prisoners: I. Criminality and psychiatric morbidity. Br J Psychiatry 181:473-480

4. Coid J, Petruckevitch A, Bebbington P, Brugha D, Jenkins R, Farrell M, Lewis G, Singleton N (2002) Ethnic differences in prisoners: II. Risk factors and psychiatric service use. Br J Psychiatry $181: 481-487$

5. Department of Health (1999) The future organisation of prison health care. http://www.dh.gov.uk/prod_consum_dh/groups/dh_ digitalassets/@dh/@en/documents/digitalasset/dh_4106031.pdf. Accessed 20 Oct 2015

6. Department of Health (1999) National service framework for mental health: modern standards and service models. http://www. dh.gov.uk/prod_consum_dh/groups/dh_digitalassets/@dh/@en/ documents/digitalasset/dh_4077209.pdf. Accessed 20 Oct 2015

7. Department of Health (2001) Changing the outlook: a strategy for developing and modernising mental health services in prisons. http://www.dh.gov.uk/prod_consum_dh/groups/dh_digitalassets/ @dh/@en/documents/digitalasset/dh_4034228.pdf. Accessed 20 Oct 2015
8. Sainsbury Centre for Mental Health (2010) Short changed: spending on prison mental health care. http://www.lincoln.ac.uk/ cjmh/docs/Short-changed.pdf. Accessed 20 Oct 2015

9. Brooker C, Gojkovic D (2009) The second national survey of mental health in-reach services in prisons. J Forens Psychiatry Psychol 20:S11-S28

10. Brewin CR, Wing JK, Mangen SP, Brugha TS, MacCarthy B (1987) Principles and practice of measuring need in the long term mentally ill: the MRC needs for care assessment. Psychol Med 17:971-981

11. Stevens A, Gabbay J (1991) Needs assessment needs assessment. Health Trends 23:20-23

12. Bebbington PE (1990) Population surveys of psychiatric disorder and the need for treatment. Soc Psychiatry Psychiatr Epidemiol 25:33-40

13. Bebbington PE, Marsden L, Brewin C, Lesage A (1996) Measuring the need for psychiatric treatment in the general population: the community version of the MRC needs for care assessment. Psychol Med 26:229-236

14. Bebbington PE, Marsden L, Brewin CR (1997) The need for psychiatric treatment in the general population: the Camberwell needs for care survey. Psychol Med 27:821-834

15. McConnell P, Bebbington $\mathrm{P}$, McClelland R, Gillespie $\mathrm{K}$, Houghton S (2002) Prevalence of psychiatric disorder and the need for psychiatric care in Northern Ireland. Population study in the District of Derry. Br J Psychiatry 181:214-219

16. Thomas SD, Slade M, McCrone P, Harty MA, Parrott J, Thornicroft G, Leese M (2008) The reliability and validity of the forensic Camberwell Assessment of Need (CANFOR): a needs assessment for forensic mental health service users. Int J Methods Psychiatr Res 17:111-120

17. Bebbington PE (1992) Assessing the need for psychiatric treatment at the district level: the role of surveys. In: Thornicroft GJ, Brewin CR, Wing JK (eds) Measuring mental health needs. Gaskell, London

18. Brewin CR, Bebbington PE, Lesage AD (1994) The MRC needs for care assessment community version instruction manual (version 30 June 1994). MRC Social Psychiatry Unit, Institute of Psychiatry, London

19. Lesage A, Fournier L, Cyr M, Toupin J, Fabian J, Gaudette G, Vanier C, Bebbington PE, Brewin C (1996) The reliability of the community version of the needs for care assessment. Psychol Med 26:237-243

20. Lewis G, Pelosi A, Araya RC, Dunn G (1992) Measuring psychiatric disorder in the community: a standardized assessment for use by lay interviewers. Psychol Med 22:465-486

21. Brown GW, Harris TO (1978) Social origins of depression: a study of psychiatric disorder in women. Tavistock, London

22. Wing JK, Babor T, Brugha T, Burke J, Cooper JE, Giel R, Jablensky A, Regier D, Sartorius N (1990) SCAN: schedules for clinical assessment in neuropsychiatry. Arch Gen Psychiatry 47:586-593

23. World Health Organization (1992) SCAN: schedules for clinical assessment in neuropsychiatry. WHO, Geneva

24. First MB, Gibbon M, Spitzer RL, Williams JBW, Benjamin LS (1997) Structured clinical interview for DSM-IV axis II personality disorders (SCID-II). American Psychiatric Press Inc, Washington, D.C.

25. Foa EB (1995) Posttraumatic stress diagnostic scale manual. National Computer Systems Inc, Singapore

26. Saunders JB, Aasland OG, Babor TF, de la Fuente JR, Grant M (1993) Development of the alcohol use disorders identification test (AUDIT): WHO collaborative project on early detection of persons with harmful alcohol consumption-II. Addiction 88:791-804 
27. Stockwell T, Murphy D, Hodgson R (1983) The severity of alcohol dependence questionnaire: its use, reliability and validity. Br J Addict 78:145-155

28. American Psychiatric Association (1994) Diagnostic and statistical manual of mental disorders, 4th edn-revised. American Psychiatric Association, Washington, D.C.

29. Coid J, Moran P, Bebbington P, Brugha T, Jenkins R, Farrell M, Lewis G, Singleton N (2009) The co-morbidity of personality disorder and clinical syndromes in prisoners. Crim Behav Ment Health 19:321-333

30. Sirdifield C, Gojkovic D, Brooker C, Ferriter M (2009) A systematic review of research relating to the epidemiology of mental health disorders in prison population: a summary of findings. J Forens Psychiatry Psychol 20:S78-S102
31. Brooker C, Repper J, Beverley C, Ferriter M, Brewer N (2003) Mental health services and prisoners: a review. http://www.dh.gov. uk/en/Publicationsandstatistics/Publications/PublicationsPolicy AndGuidance/DH_4084149. Accessed 20 Oct 2015

32. Spiers N, Qassem T, Bebbington PE, McManus S, King M, Jenkins R, Brugha TS (2016) Increasing treatment, continuing burden: the prevalence and treatment of common mental disorders in the English national population, 1993 to 2007. Br J Psychiatry 209:150-156

33. Ministry of Justice (2010) Breaking the cycle effective punishment, rehabilitation and sentencing of offenders. http://www.jus tice.gov.uk/consultations/breaking-cycle-071210.htm. Accessed 20 Oct 2015 